\title{
O mercado de trabalho na região metropolitana de São Paulo
}

\author{
MARISE BORÉM PIMENTA HOFFMAN N \\ e SÉrgio Eduardo Arbulu MEndon ÇA
}

\section{Introdução}

$\mathrm{E}$ Ste ARTIgo analisa a evolução recente e as principais características do mercado de trabalho da Região M etropolitana de São Paulo, utilizando indicadores gerados a partir da base de dados da Pesquisa de Emprego e D esemprego (PED) realizada pelo Departamento Intersindical de Estatística e Estudos Sócio-E conômicos (DIEESE) e a Fundação Sistema Estadual de Análise de $D$ ados (Seade) na Região M etropolitana de São Paulo desde 1995.

A PED é uma pesquisa domiciliar amostral que produz indicadores estatísticos sobre a inserção da população de dez anos e mais no mercado de trabalho. Além da Região M etropolitana de São Paulo, é realizada também no D istrito Federal e nas regiões metropolitanas de Porto Alegre, Belo H orizonte, Salvador e Recife (Troyano, 1985; DIEESE-Seade, 1995; M endonça-H offmann, 1999; Sanches, 2002).

Esta pesquisa utiliza meto dologia especialmente desenvolvida para captar, de forma acurada, os diversos aspectos da inserção da população ativa neste mercado de trabalho e, em especial, a situação de desemprego e as formas de trabaIho geralmente consideradas como mais vulneráveis ou precarizadas.

Seu desenho amostral permite acompanhar mensalmente a evolução do mercado de trabalho de cada uma das regiões acima apontadas e produzir indicadores anuais e para a realização de estudos em profundidade sobre aspectos de segmentos específicos da população ou de subgrupos diferenciados de postos de trabalho.

Este artigo pretende, também, com a apresentação e a análise de indicadores estatísticos proporcionados pela PED, contribuir para ampliar o conhecimento empírico sobre a capacidade de o mercado de trabalho incorporar a força de trabalho disponível da Região M etropolitana de São Paulo, de 1989 a 2001, e para aumentar o conhecimento sobre as possibilidades de uso do banco de dados desta pesquisa. Para tanto, atualiza vários indicadores utilizados no livro A situação do trabalho no Brasil, produzido e publicado pelo DIEESE, em 2001 (ver bibliografia). 
I nicialmente, são apresentados dados sobre a evolução da População E conomicamente A tiva (PEA) e da ocupação total, com o propósito de quantificar o tamanho do mercado de trabalho desta região e a evolução da sua brecha ocupacional. D epois, são analisados vários indicadores, a fim de caracterizar a ocupação gerada e o dinamismo ocupacional dos grandes setores, dos principais ramos de atividade econômica e das diversas formas de inserção dos trabalhadores neste mercado. São também apresentados indicadores que, em alguma medida, informam sobre a flexibilização da contratação do trabal ho assalariado e sobre os rendimentos do trabalho. A análise deste conjunto de estatísticas confirma a persistência de um medíocre dinamismo de geração de postos de trabal ho neste mercado, em especial no setor industrial, e o aumento da precarização das condições de trabalho. Por último, como complemento necessário ao propósito deste artigo, são apresentados e analisados indicadores que permitem avaliar a intensidade do desemprego, sua composição e características específicas.

\section{A população economicamente ativa na região metropolitana de São Paulo (1989-2001)}

A R egião M etropolitana de São Paulo (R M SP) é o principal conglomerado urbano do país, composto por 39 municípios, integrados espacial e economicamente, do ponto de vista da produção e também dos mercados de trabalho. Em seu interior existe ampla mobilidade da força de trabal ho residente nos diferentes municípios e a oferta de postos de trabalho, em cada cidade, depende da dinâmica de uma produção cada vez mais integrada na região.

Em 2001, a população residente estimada no município de São Paulo representava cerca de $60 \%$ do total de habitantes desta Região M etropolitana. A capital e as cidades que compõem o G rande ABC constituíam-se nos dois grandes pólos de geração de postos de trabalho da região.

A Tabela 1 apresenta estimativas anuais da população total residente na Região M etropolitana de São Paulo e de parcelas desta po pulação inseridas no mercado de trabalho metropolitano, nas condições de ocupada ou desempregada. E stas estimativas permitem não só quantificar o tamanho deste mercado, como estimar a brecha ou o déficit de postos de trabalho, expresso pelo volume de trabalhadores desempregados

Para 1989, estima-se a população residente em 14.804 milhões de pessoas. D estas, cerca de 7.502 milhões participavam deste mercado de trabalho como população economicamente ativa. N este ano, foram gerados postos de trabal ho suficientes para 6.438 milhões trabalhadores, ou seja, restaram como desempregados aproximadamente 614 mil.

No final do período estudado, em 2001, o volume de ocupados aumentou, passando para 7.596 milhões trabalhadores. No entanto, o déficit de postos de trabalho cresceu. Passaram à condição de desempregados 1.622 milhões trabaIhadores, uma vez que a geração de 1.158 milhões novos postos de trabalho, 
entre 1989 e 2001, não foi suficiente para atender ao crescimento da PEA, que, neste período, aumentou para 2,166 milhões pessoas.

Tabela 1

Estimativas M édias da População Total, População em I dade Ativa e M enores de 10 anos. Região M etropolitana de São Paulo (1989-2001)

\begin{tabular}{|c|c|c|c|c|c|c|}
\hline & & & & & (om 1. & 10 pessos \\
\hline Condlçlo de atividade & 1989 & 1992 & 1997 & 1999 & 2000 & 2001 \\
\hline TOTAL & 14.804 & 15.642 & 16.782 & 17.212 & 17.431 & 17.659 \\
\hline Populaçăo em Idade Ativa (10 anos ou mais) & 11.541 & 12.574 & 13.925 & 14.284 & 14.465 & 14.655 \\
\hline Populaça Economicamente Ativa & 7.052 & 7.733 & 8.592 & 8.885 & 9.041 & 9.218 \\
\hline Ocupados & 6.438 & 6.558 & 7.217 & 7.170 & 7.450 & 7.596 \\
\hline Desempregados & 614 & 1.175 & 1.375 & 1.715 & 1.591 & 1.622 \\
\hline Inativos de 10 anos ou mais & 4.489 & 4.841 & 5.333 & 5.399 & 5.424 & 5.437 \\
\hline Menores de 10 anos & 3.263 & 3.068 & 2.857 & 2.928 & 2.966 & 3.004 \\
\hline
\end{tabular}

Fonte: Convênio Dieese/ Seade. PED - (Pesquisa de Emprego e D esemprego).

O Gráfico a seguir permite comparar o crescimento do nível de ocupação total e o da PEA, ao longo dos últimos anos. A taxa anual média de crescimento da ocupação, de 1989 a 2001, foi de apenas 1,4\%, enquanto a da PEA foi de 2,3\%.

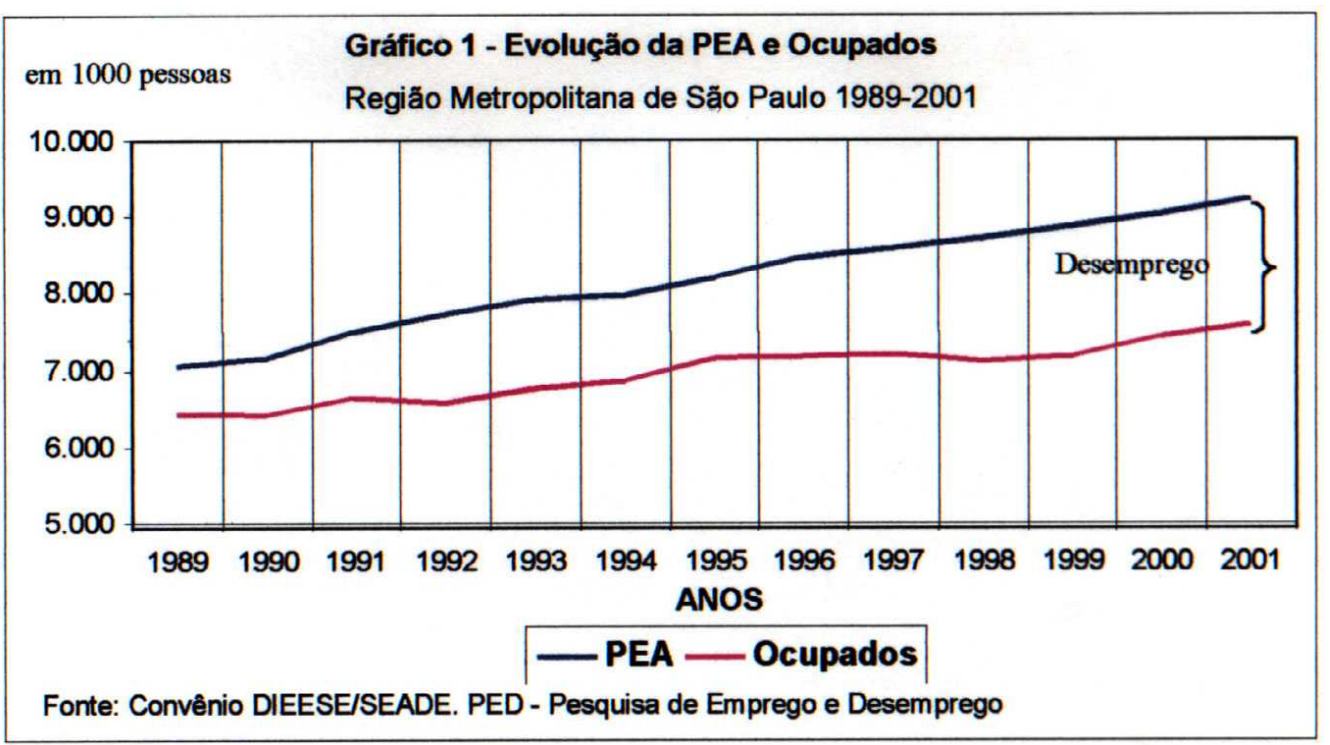

A análise das taxas de participação por atributos pessoais permite qualificar o crescimento da PEA no período em estudo.

As taxas de participação ${ }^{1}$ por atributos pessoais indicam que, entre 1989 e 2001, o crescimento da PEA foi acompanhado de modificações acentuadas e divergentes nas respectivas taxas específicas de participação. Verificou-se leve crescimento da taxa de participação total, indicativo de que o crescimento da PEA, neste período, foi resultado não só do crescimento da população em idade ativa 
(dez anos e mais), como também da intensificação da participação desta população no mercado de trabalho, em especial mulheres e cônjuges. As taxas de participação aumentaram nas faixas etárias de 25 a 39 anos e de quarenta a 59 anos e diminuíram entre as crianças e jovens com até dezessete anos. Para a faixa de dezoito a 24 anos, permaneceram estáveis, e, para os idosos (sessenta anos e mais), apresentaram leve crescimento.

Tabela 2

Taxa de Participação, segundo Atributos Pessoais

Região M etropolitana de São Paulo (1989-2001)

\begin{tabular}{lcccccc}
\hline Atributos & $\mathbf{1 9 8 9}$ & $\mathbf{1 9 9 2}$ & $\mathbf{1 9 9 7}$ & $\mathbf{1 9 9 9}$ & $\mathbf{2 0 0 0}$ & $\mathbf{2 0 0 1}$ \\
\hline TOTAL & $\mathbf{6 1 , 1}$ & $\mathbf{6 1 , 5}$ & $\mathbf{6 1 , 7}$ & $\mathbf{6 2 , 2}$ & $\mathbf{6 2 , 5}$ & $\mathbf{6 2 , 9}$ \\
& & & & & & \\
Posição no Domicilio & & & & & & \\
Chefe & 81,1 & 79,7 & 79,4 & 78,2 & 78,1 & $\mathbf{7 7 , 1}$ \\
Cônjuge & 39,3 & 44,3 & 48,9 & 51,6 & 52,1 & 53,5 \\
Filho & 56,8 & 55,1 & 53,0 & 53,6 & 54,4 & 55,4 \\
Outros & 63,8 & 63,2 & 61,5 & 60,6 & 59,5 & 59,8 \\
& & & & & & \\
Sexo & & & & & & \\
Homens & 77,3 & 75,7 & 73,9 & 73,4 & 73,4 & 72,9 \\
Mulheres & 46,1 & 48,4 & 50,5 & 52,0 & 52,7 & 53,8 \\
& & & & & & \\
Faixa Etária & & & & & & \\
10 a 14 Anos & 14,6 & 12,5 & 9,7 & 7,1 & 6,6 & 7,2 \\
15 a 17 Anos & 64,8 & 58,9 & 51,1 & 47,6 & 46,5 & 47,2 \\
18 a 24 Anos & 80,0 & 80,4 & 78,4 & 79,5 & $\mathbf{8 1 , 0}$ & $\mathbf{8 1 , 3}$ \\
25 a 39 Anos & 76,6 & 79,3 & 81,2 & 82,6 & 82,8 & 83,3 \\
40 a 59 Anos & 64,0 & 66,3 & 69,1 & 69,7 & 70,2 & 70,0 \\
60 Anos e Mais & 22,0 & 22,1 & 22,3 & 22,1 & 21,8 & 22,2 \\
\hline
\end{tabular}

Fonte: Convênio D ieese/ Seade. PED - (Pesquisa de Emprego e D esemprego).

Por sua vez, os chefes de domicílio retraíram sua participação, compensada pela maior presença dos cônjuges, elevada sistematicamente (a taxa passou de 39,3\% em 1989, para 53,5\%, em 2001). D a mesma forma, a participação das muIheres também cresceu ao longo deste perío do (era de 46,1\% em 1989 e chegou a 53,8\%, em 2001), enquanto a dos homens reduziu-se: passou para $72,9 \%$ neste último ano, quando, em 1989, alcançava 77,3\%.

Este comportamento anterior, com forte presença das mulheres e cônjuges no mercado de trabalho e simultânea retração da participação dos chefes e trabaIhadores do sexo masculino, revela a deterioração das condições do mercado de trabalho. A maior participação feminina, neste período, certamente está associada não só à tendência histórica de crescente incorporação da mulher ao mercado de trabal ho como também ao aumento do desemprego e da inatividade entre os homens e chefes de domicílio. 
As modificações acima destacadas permitem considerar que o déficit ocupacional só não foi maior devido a uma acentuada retração da participação dos homens e chefes do domicílio (usualmente incorporados à força de trabalho), que, em decorrência da perda do dinamismo do mercado de trabalho, foram levados a uma situação de inatividade. Esta deterioração do mercado de trabalho é revelada pelos indicadores da evolução e pelas características da ocupação, dos rendimentos proporcionados pelo trabalho e pela gravidade da situação do desemprego do período.

\section{E volução e características dos postos de trabalho (1989-2001)}

O baixo crescimento do nível de ocupação total na RM SP foi resultado do desempenho diferenciado dos setores de atividade econômica, bem como do débil crescimento econômico do país. O s anos de 1990, como já é amplamente reconhecido, caracterizaram-se por modificações na proposta de estabelecer um novo modelo de crescimento e desenvolvimento econômico, dentro de uma nova ordem internacional, a chamada globalização.

No caso do Brasil, um dos efeitos perversos mais notórios da política econômica adotada foi o baixo crescimento econômico e a onda de (des)estruturação do parque industrial, com reflexo direto na capacidade de geração de postos de trabalho. O E stado de São Paulo, e em especial a RM SP, foram amplamente afetados por concentrarem a maior parte do parque industrial do país.

$\mathrm{N}$ este período, verificou-se uma queda extraordinária do nível de emprego industrial, compensada, em parte, pelo crescimento da ocupação nos serviços e no comércio, cumprindo seus tradicionais papéis de absorver parte da mão-deobra excedente. Vale lembrar que os dois setores passaram também por um processo de reestruturação que implicou redução da capacidade de geração de empregos em alguns segmentos economicamente mais dinâmicos, como por exemplo, o ramo creditício e financeiro, e o comércio de produtos de consumo de massa que, cada vez mais, passou a ser realizado por redes de supermercados e outros grandes revendedores de produtos duráveis. Já na construção civil, devido à redução dos investimentos, o emprego apresentou leve crescimento, concentrado nas atividades de reformas e manutenção de edificações.

O Gráfico 2 permite comparar a evolução dos índices de ocupação total e por setor (indústria, comércio e serviços). A Tabela 3 apresenta estimativas dos níveis de ocupação segundo setores de atividade econômica.

O s dados da Tabela anterior evidenciam queda acentuada na ocupação industrial, no início dos anos de 1990. Entre 1989 e 1992, foram eliminados 394 mil postos de trabalho. Nos anos seguintes, embora com quedas menores, a redução anual dos postos de trabalho persistiu. No final da década (1999), havia o menor nível de ocupação industrial (1.405 milhões ocupados), resultado da eliminação, em dez anos, de 720 mil postos de trabalho no setor. Em 2000, com a retomada do crescimento do setor, foi gerado saldo líquido de 78 mil novos 
postos de trabalho. No entanto, em 2001, com a desaceleração do crescimento, apenas, 29 mil novos postos de trabal ho foram gerados na indústria. Como resultado desta desfavorável evolução, a participação relativa do emprego industrial perdeu importância no total de ocupações da R M SP. Por outro lado, aumentaram as respectivas proporções dos setores do Comércio e especial mente dos Serviços (Tabela 4).

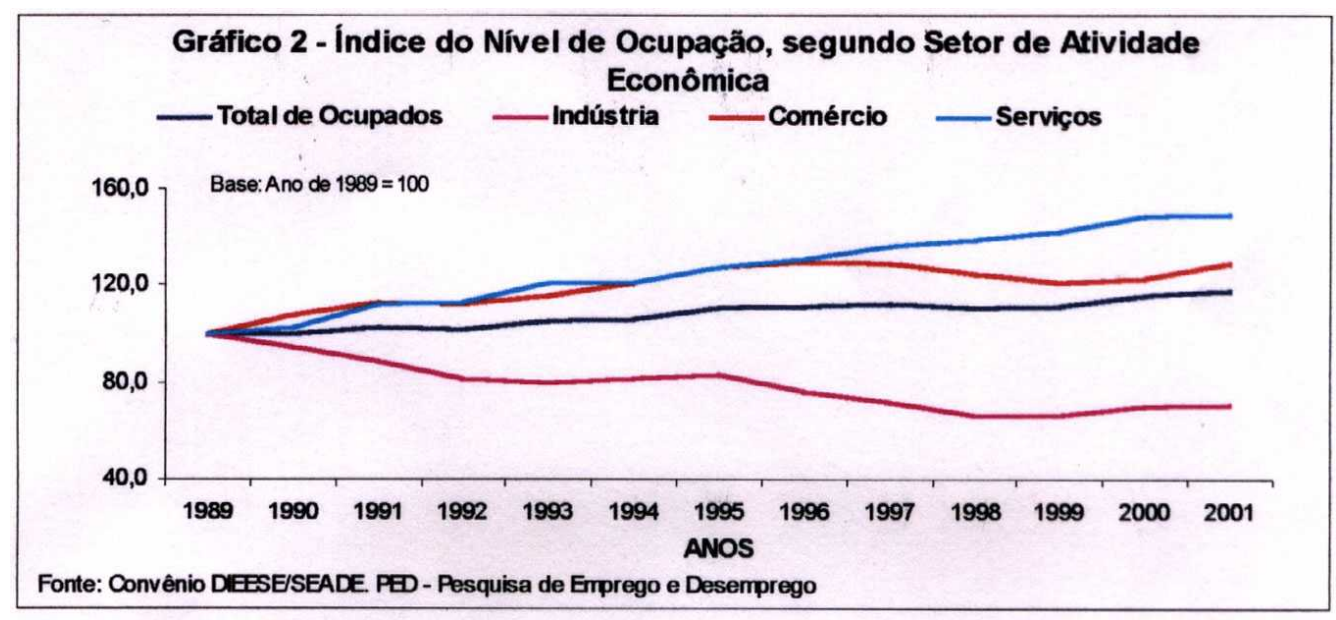

Tabela 3

Estimativa dos 0 cupados, segundo Setor de Atividade Econômica Região M etropolitana de São Paulo (1989-2001)

\begin{tabular}{lcccccc}
\hline Setor de Atividade & 1989 & 1992 & 1997 & 1999 & 2000 & 2001 \\
\hline TOTAL & 6.438 & 6.558 & 7.217 & 7.170 & 7.450 & 7.596 \\
Indústria & 2.125 & 1.731 & 1.516 & 1.405 & 1.483 & 1.512 \\
Comércio & 953 & 1.069 & 1.227 & 1.154 & 1.170 & 1.231 \\
Serviços & 2.659 & 3.017 & 3.630 & 3.779 & 3.949 & 3.973 \\
Demais's & 701 & 741 & 844 & 832 & 848 & 880
\end{tabular}

Fonte: Convênio Dieese/ Seade. PED - (Pesquisa de Emprego e D esemprego).

(1) Engloba Construção Civil, Serviços D omésticos etc.

Em 1989, os empregos gerados pelo setor industrial representavam 33\% dos postos de trabalho da região e, ao final do período analisado, esta parcela reduziu-se para 20\%. O setor de serviços, que já era o principal responsável pela geração de postos de trabalho, elevou sua participação no total de postos gerados, passando de 41,3\%, no início do período, para 52,3\%, em 2001. Já a proporção das ocupações geradas no comércio passou de $14,8 \%$ para $16,2 \%$.

A Tabela 4 mostra também que os principais ramos do setor industrial diminuíram suas capacidades relativas de geração de postos de trabal ho, em especial o segmento metalmecânico. Sua participação no total de postos de trabalho 
da RM SP se reduziu em quase $50 \%$ (passou de $14,2 \%$ para $7,4 \%$ ). N este item, outro ramo que merece destaque é o vestuário e têxtil, cuja contribuição na geração de postos de trabalho passou de 5,9\% para 3,5\%

Tabela 4

D istribuição dos 0 cupados, segundo Setores e Ramos de Atividade Região M etropolitana de São Paulo (1989-2001)

\begin{tabular}{lccc}
\hline Setores e Ramos de Atividade & $\mathbf{1 9 8 9}$ & $\mathbf{1 9 9 9}$ & $\mathbf{2 0 0 1}$ \\
\hline TOTAL & $\mathbf{1 0 0 , 0}$ & $\mathbf{1 0 0 , 0}$ & $\mathbf{1 0 0 , 0}$ \\
Indústria & $\mathbf{3 3 , 0}$ & $\mathbf{1 9 , 6}$ & $\mathbf{1 9 , 9}$ \\
Metal-Mecânica & 14,2 & 7,3 & 7,4 \\
Química e Borracha & 3,9 & 2,2 & 2,4 \\
Vestuário e Têxtil & 5,9 & 3,2 & 3,5 \\
Alimentação & 1,8 & 1,3 & 1,3 \\
Gráfica e Papel & 2,3 & 2,0 & 2,1 \\
Outras & 4,8 & 3,5 & 3,4 \\
Construção Civil & $\mathbf{3 , 9}$ & $\mathbf{2 , 3}$ & $\mathbf{2 , 6}$ \\
Comércio & $\mathbf{1 4 , 8}$ & $\mathbf{1 6 , 1}$ & $\mathbf{1 6 , 2}$ \\
Serviços & $\mathbf{4 1 , 3}$ & $\mathbf{5 2 , 7}$ & $\mathbf{5 2 , 3}$ \\
Reformas & 1,6 & 3,1 & 2,7 \\
Oficina Mecânica & 1,7 & 2,0 & 2,1 \\
Limpeza e Outras Oficinas & 4,4 & 4,4 & 4,6 \\
Transportes & 4,3 & 4,8 & 4,6 \\
Especializados & 3,6 & 6,0 & $\mathbf{5 , 8}$ \\
Administração e Utilidade Pública & $\mathbf{4 , 8}$ & $\mathbf{4 , 9}$ & 4,8 \\
Creditícios & 4,0 & 2,6 & 2,3 \\
Alimentaçăo & 3,6 & $\mathbf{5 , 3}$ & 5,4 \\
Educação & 3,2 & 3,8 & 3,7 \\
Saúde & 3,0 & 4,0 & 4,0 \\
Auxiliares & 1,2 & 3,2 & 3,8 \\
Outros & 5,9 & $\mathbf{8 , 6}$ & 8,5 \\
Serviços Domésticos & $\mathbf{8 , 9}$ & $\mathbf{8 , 4}$ \\
Demais & $\mathbf{6 , 1}$ & $\mathbf{0 , 5}$ & $\mathbf{0 , 6}$ \\
\hline \hline
\end{tabular}

Fonte: Convênio Dieese/ Seade. PED - (Pesquisa de Emprego e D esemprego).

N o setor de Serviços, com exceção dos serviços creditícios e financeiros, praticamente to dos os demais ramos, que tradicio nal mente absorvem muita mãode-obra, elevaram suas respectivas participações no total das ocupações da região. O s destaques foram os serviços de alimentação, oficinas mecânicas, serviços auxiliares e serviços especializados, além dos serviços domésticos, que tiveram notável expansão.

A participação do trabalho na construção civil foi basicamente sustentada pela expansão dos trabalhos em reformas (identificado nesta Tabela no setor de Serviços). 
A companhando a queda do emprego industrial e as modificações na estrutura setorial da ocupação total, verificou-se lento crescimento do trabal ho assalariado e expansão acentuada do trabalho dos autônomos e dos empregados domésticos, como pode ser visualizado no Gráfico 3.

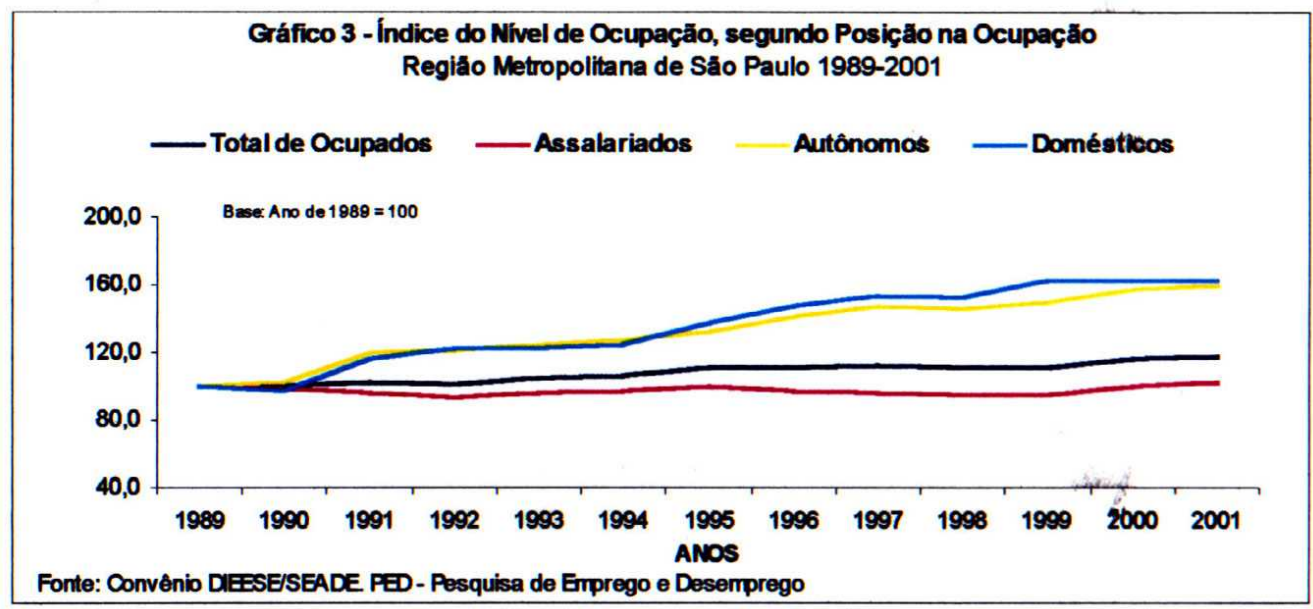

Em termos absolutos, entre 1989 e 2001 foram gerados apenas 144 mil novos postos de trabalho assalariados, enquanto para a categoria de trabalho autônomo, foram 599 mil novas vagas e para o emprego doméstico, 245 mil.

Tabela 5

Estimativa dos 0 cupados, segundo Posição na O cupação

Região M etropolitana de São Paulo (1989-2001)

\begin{tabular}{lcccccc} 
& \multicolumn{5}{c}{ (em 1.000 pessoas) } \\
\hline Posiçăo na Ocupaçăo & 1989 & 1992 & 1997 & 1999 & 2000 & 2001 \\
\hline TOTAL & 6.438 & 6.558 & 7.217 & 7.170 & 7.450 & 7596 \\
Assalarlados (1) & & & & & 4.619 & 4.786 \\
Do Selor Privado & 4.642 & 4.368 & 4.446 & 4.402 & 4.619 \\
Com Carteira Assinada & 3.998 & 3.659 & 3.839 & 3.786 & 3.993 & 4.174 \\
Sem Carteira Assinada & 3.412 & 3.063 & 2.981 & 2.897 & 2.958 & 3.098 \\
Do Setor Público & 586 & 597 & 859 & 896 & 1.036 & 1.076 \\
Autonomo & 631 & 702 & 599 & 609 & 626 & 609 \\
Trabalha para Empresa & 1.004 & 1.220 & 1.479 & 1.506 & 1.579 & 1.603 \\
Trabalha para o Público & 354 & 420 & 544 & 583 & 615 & 633 \\
Empregadores & 650 & 793 & 932 & 922 & 968 & 972 \\
Empregados Dombsticos & 264 & 315 & 433 & 387 & 380 & 357 \\
Demals & 393 & 479 & 606 & 638 & 641 & 638 \\
& 135 & 176 & 253 & 237 & 231 & 212 \\
\hline
\end{tabular}

Fonte: C onvênio D ieese/ Seade. PED - (Pesquisa de Emprego e D esemprego).

(1) Incluindo os assalariados que não sabem o tipo de empresa em que trabalham.

0 crescimento do trabalho assalariado entre 1989-2001 foi resultado da acentuada contratação sem carteira assinada pelo setor privado (490 mil novos trabalhadores), compensando a eliminação dos 314 mil postos de trabalho de assalariados contratados com carteira, neste período. 0 emprego no setor público também decresceu, porém em proporção bem menor: foram eliminados 22 mil 
postos de trabalho. I sto representou redução de 3,5\% dos postos gerados por este setor nesta R egião M etropolitana. Já para os assalariados no setor privado com carteira assinada, a redução foi de $9,2 \%$

Comparado às demais categorias ocupacionais, o trabalho assalariado reduziu sua representação no total de postos de trabal ho gerados, especialmente 0 assalariamento com carteira de trabal ho assinada (Tabela 6).

Tabela 6

D istribuição dos 0 cupados, segundo Posição na O cupação

Região M etropolitana de São Paulo (1989-2001)

\begin{tabular}{lccc}
\hline Posição na Ocupação & 1989 & 1999 & $\mathbf{2 0 0 1}$ \\
\hline TOTAL & 100,0 & 100,0 & 100,0 \\
Assalariados (1) & 72,1 & 61,4 & 63,0 \\
Do Setor Privado & 62,1 & 52,8 & 55,0 \\
Com Carteira Assinada & 53,0 & 40,4 & 40,8 \\
Sem Carteira Assinada & 9,1 & 12,5 & 14,2 \\
Do Setor Público & 9,8 & 8,5 & 8,0 \\
Autônomo & 15,6 & 21,0 & 21,1 \\
Trabalha para Empresa & 5,5 & 8,1 & 8,3 \\
Trabalha para o Público & 10,1 & 12,9 & 12,8 \\
Empregadores & 4,1 & 5,4 & 4,7 \\
Empregados Domésticos & 6,1 & $\mathbf{8 , 9}$ & $\mathbf{8 , 4}$ \\
Demais & 2,0 & 3,3 & $\mathbf{2 , 7}$ \\
\hline
\end{tabular}

Fonte: C onvênio Dieese/ Seade. PED - (Pesquisa de Emprego e D esemprego).

(1) Incluindo os assalariados que não sabem o tipo de empresa em que trabalham.

A proporção do conjunto de assalariados sobre o total de ocupados passou de $72,1 \%$, em 1989, para 63\% enquanto a participação dos assalariados sem carteira, contratados no setor privado, elevou-se, passando de 9,1\%, em 1989, para $14,2 \%$, em 2001. Por sua vez, os autônomos, neste último ano, passaram a representar $21,1 \%$ do total ocupados e o emprego doméstico, 8,4\%, ultrapassando a respectiva proporção do emprego do setor público na região. Acompanhando a queda do dinamismo de geração de postos de trabal ho assalariado, as estatísticas das horas semanais efetivamente trabal hadas, ao longo do período, indicam persistência de elevada proporção, acima de $40 \%$ de assalariados, trabalhando 45 ou mais horas semanais (Tabela 7).

Paralelamente, o processo de flexibilização das formas de contratação de trabalho nas empresas privadas e no setor público foi acelerado. Além da tradicional contratação direta do assalariado sem carteira de trabalho, ganhou força a terceirização, com a contratação de empresas prestado ras de serviços e a de trabaIhadores autônomos. 


\section{Tabela 7}

D istribuição dos Assalariados, segundo Classes de H oras Semanais M édias

Trabalhadas e J ornada Semanal M édia de Trabalho

Região M etropolitana de São Paulo (1989-2001)

\begin{tabular}{lccc}
\hline Horas Semanais Trabalhadas & 1989 & 1999 & 2001 \\
\hline Classes de Horas & \multicolumn{3}{c}{ em norcentagem } \\
$\quad$ Total & 100,0 & 100,0 & 100,0 \\
$\quad$ Menos de 30 horas & 6,3 & 9,0 & 8,5 \\
De 30 a 39 horas & 11,6 & 15,8 & 18,3 \\
De 40 a 44 horas & 39,4 & 32,8 & 30,0 \\
45 horas ou mais & 42,7 & 42,4 & 43,2 \\
& & Heras & \\
Jomada Semanal Média de Trabalho & 44 & 43 & 43 \\
\hline
\end{tabular}

Fonte: Convênio D ieese/ Seade. PED - (Pesquisa de Emprego e D esemprego).

N ota: Exclusive os assalariados que não trabalharam na semana.

A Tabela 8 mostra que os percentuais de postos de trabal ho destas formas de contratação el evaram-se de 20,9\%, em 1989, para 35,4\%, em 2001. 0 principal é o assalariamento sem carteira de trabalho assinada, que passou a representar, em $2001,21,2 \%$ do total de postos de trabalho gerados pelo setor público e pelas empresas privadas. É perceptível o acentuado crescimento das formas mais recentes de flexibilização, embora ainda representem proporções menores do total dos postos de trabalho flexibilizados.

\section{Tabela 8}

D istribuição dos Postos de Trabalho gerados por E mpresas Privadas ou Setor Público, Segundo Formas de Construção

Região M etropolitana de São Paulo (1989-2001)

\begin{tabular}{lccc}
\hline Formas de Contratação & 1989 & 1999 & 2001 \\
\hline Total de Postos de Trabalho & 100,0 & 100,0 & 100,0 \\
Contratação Flexibilizada & 20,9 & 33,1 & 35,4 \\
Assalariados Contratados Diretamente & & & \\
sem Carteira Assinada, pelo Setor Privado & 11,6 & 17,9 & 19,4 \\
sem Carteira Assinada, pelo Setor Público & 0,9 & 1,7 & 1,8 \\
Assalariados Contratados em Serviços Terceirizados & 2,4 & 4,0 & 4,8 \\
Autônomos que Trabalham para 1 Empresa & 6,0 & 9,5 & 9,4 \\
Contratação Nazo Flexibilizada & 79,1 & 66,9 & 64,6 \\
Assalariados Contratados Diretamente & & & \\
com Carteira Assinada, pelo Setor Privado & 67,3 & 56,0 & 54,9 \\
com Carteira Assinada, pelo Setor Público & 6,3 & 3,7 & 3,2 \\
Estatutário pelo Setor Público & 5,4 & 7,2 & 6,6 \\
\hline
\end{tabular}

Fonte: Convênio D ieese/ Seade. PED - (Pesquisa de Emprego e D esemprego). 


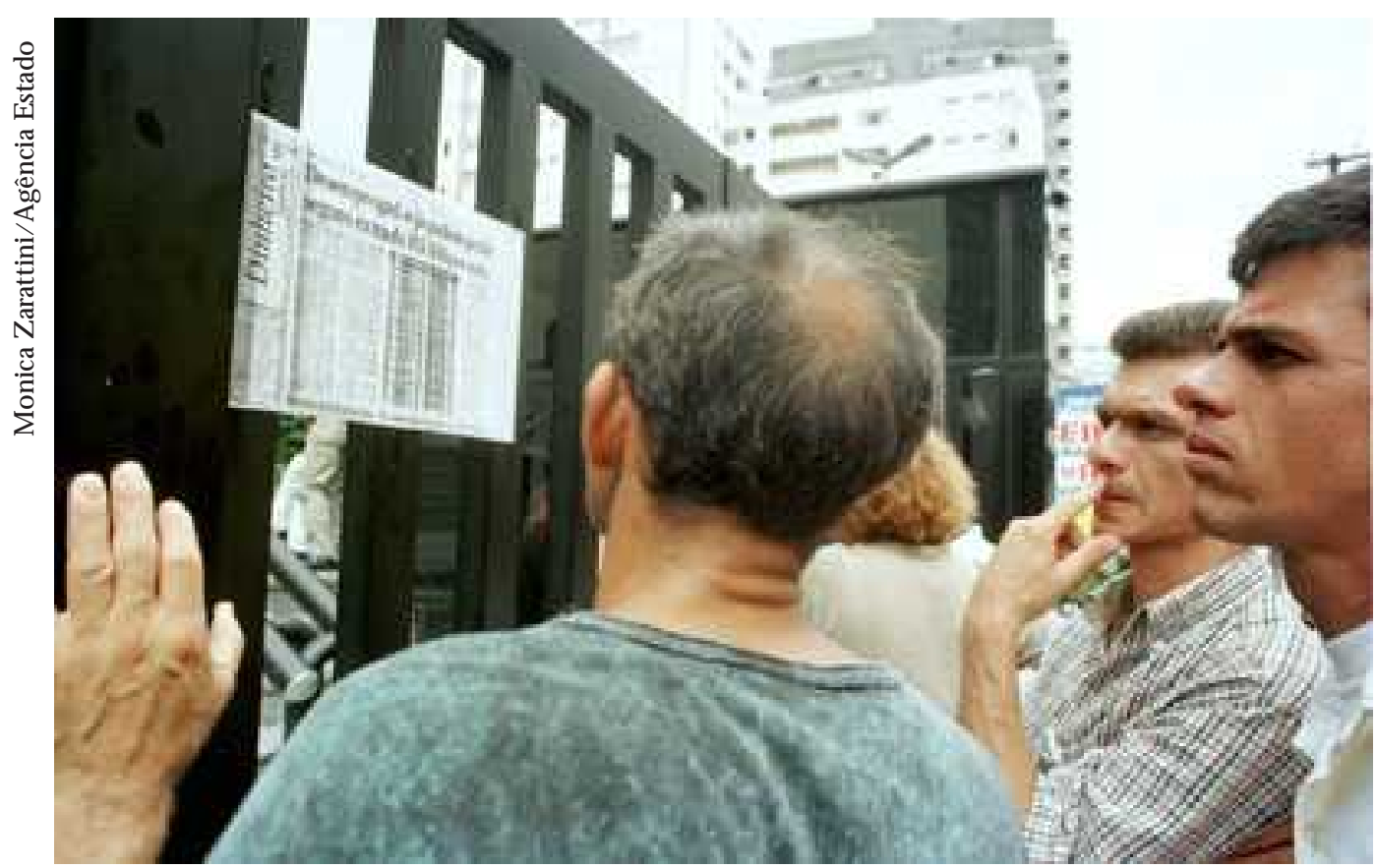

D esempregados na porta do Palácio dos Trabalhadores, da Força Sindical.

\section{E volução dos rendimentos do trabalho 1989-2001}

A Tabela 9 mostra a evolução dos rendimentos médios reais do conjunto de ocupados e para os três grandes setores de atividade econômica. H ouve queda dos rendimentos do trabalho, no início dos anos de 1990, em decorrência da aceleração do processo inflacionário, em finais dos anos de 1980 e que persistiu até parte da década seguinte.

A pós a adoção do plano Real, em 1994, com o controle da inflação, começou uma retomada do crescimento da renda. No entanto, apenas até 1997. Em 1998, foram registradas novamente perdas nos rendimentos do trabalho. E $m$ 2001, o valor médio para o conjunto dos ocupados era $30 \%$ inferior ao registrado em 1989 e próximo ao verificado em 1992 (menor valor real desde 1985). A pior situação foi observada no comércio e a melhor, nos serviços. N este ano, os rendimentos reais nos dois setores eram, respectivamente, 40,9\% e 25,4\% inferiores a 1989. N a indústria, a perda chegou a $29,4 \%$

Cabe lembrar que a evolução dos rendimentos médios reais expressa não só a perda de seu poder aquisitivo em decorrência da inflação, mas também a queda causada pelas modificações nas características dos postos de trabal ho gerados. D esta forma, por exemplo, a maior perda no rendimento médio dos ocupados no comércio possivelmente está bastante associada ao aumento do número de trabalhadores informais no setor, em especial do autônomo para o público (particularmente, vendedores ambulantes), cujos rendimentos são em geral muito baixos. 
Tabela 9

Rendimento M édio Real dos 0 cupados no Trabalho Principal (1), segundo Setor de Atividade E conômica

Região M etropolitana de São Paulo (1989-2001)

\begin{tabular}{|c|c|c|c|c|c|c|}
\hline Setor de Atividade & 1989 & 1992 & 1997 & 1999 & 2000 & 2001 \\
\hline \multicolumn{7}{|l|}{ Ocupados (2) } \\
\hline Valor absoluto ${ }^{3}$ & 1.253 & 834 & 1.126 & 1.028 & 966 & 880 \\
\hline Indice ${ }^{4}$ & 100,0 & 66,6 & 89,9 & 82,0 & 77,1 & 70,2 \\
\hline \multicolumn{7}{|l|}{ Indústria } \\
\hline Valor absoluto ${ }^{3}$ & 1.372 & 1.016 & 1.272 & 1.126 & 1.080 & 969 \\
\hline Índice ${ }^{4}$ & 100,0 & 74,0 & 92,7 & 82,1 & 78,7 & 70,6 \\
\hline \multicolumn{7}{|l|}{ Comércio } \\
\hline Valor absoluto ${ }^{3}$ & 1.203 & 697 & 992 & 836 & 758 & 711 \\
\hline Indice ${ }^{4}$ & 100,0 & 57,9 & 82,4 & 69,5 & 63,0 & 59,1 \\
\hline \multicolumn{7}{|l|}{ Serviços } \\
\hline Valor absoluto ${ }^{3}$ & 1.335 & 886 & 1.241 & 1.169 & 1.096 & 996 \\
\hline Indice ${ }^{4}$ & 100,0 & 66,4 & 93,0 & 87,6 & 82,1 & 74,6 \\
\hline
\end{tabular}

Fonte: Convênio Dieese/ Seade. PED - (Pesquisa de Emprego e D esemprego).

(1) Exclusive os assalariados e os empregados domésticos assalariados que não tiveram remuneração no mês, os trabalhadores familiares sem remuneração sal arial e os trabalhadores que ganharam exclusivamente em espécie ou beneficio. Inflator utilizado: ICV do Dieese.

(2) Inclusive os que não declararam o setor de atividade no qual trabalharam.

(3) Valores em reais de $\mathrm{N}$ ovembro de 2001.

(4) Ano de $1989=100$.

O G ráfico seguinte permite visualizar a evolução do rendimento médio real para o conjunto dos ocupados na região.

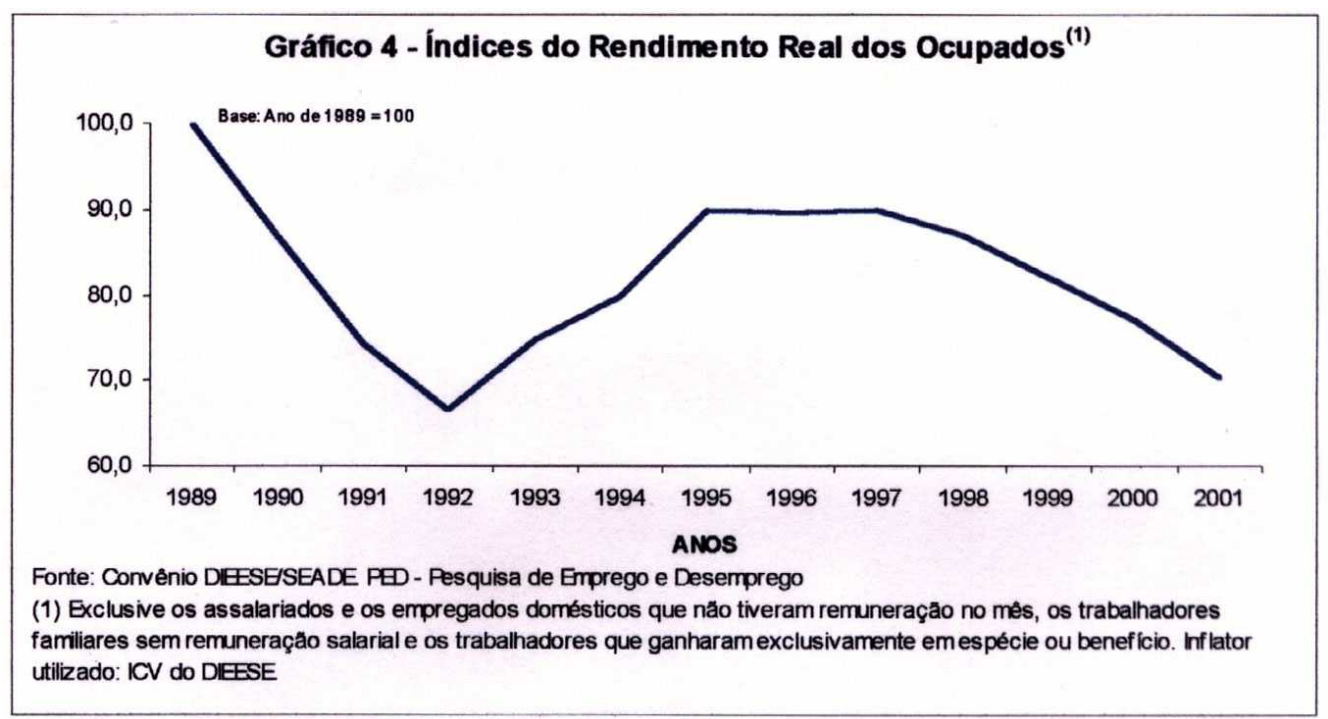


O s valores dos rendimentos médios reais dos trabalhadores assalariados, dos autônomos e dos empregados domésticos são apresentados na Tabela 10.

Tabela 10

Rendimento M édio Real dos 0 cupados no Trabalho Principal (1)

Segundo Posição na O cupação

Região M etropolitana de São Paulo (1989-2001)

\begin{tabular}{lccccccc}
\hline Posiçắo na Ocupaçăo & 1989 & 1992 & 1997 & 1999 & 2000 & 2001 & $\begin{array}{c}\text { Variaçäo\% } \\
\text { 2001/89 }\end{array}$ \\
\hline Ocupados (2) & 1.253 & 834 & 1.126 & 1.028 & 966 & 880 & $-29,8$ \\
Assalariados (3) & 1.262 & 897 & 1.113 & 1.053 & $\mathbf{9 8 2}$ & $\mathbf{9 1 2}$ & $\mathbf{- 2 7 , 7}$ \\
Setor Privado & 1.194 & 852 & 1.054 & 992 & 929 & 865 & $-27,6$ \\
com carteira & 1.290 & 934 & 1.162 & 1.088 & 1.021 & 955 & -26 \\
sem carteira & 565 & 407 & 667 & 675 & 657 & 595 & 5,3 \\
Setor Público & 1.691 & 1.125 & 1.469 & 1.425 & 1.315 & 1.222 & $-27,7$ \\
Autónomos & 1.156 & 596 & 920 & 770 & 743 & 673 & $-41,8$ \\
para o Público & 1.043 & 516 & 815 & 693 & 651 & 614 & $-41,1$ \\
para Empresa & 1.343 & 739 & 1.097 & 887 & 883 & 757 & $-43,6$ \\
Doméstico & 298 & 219 & 393 & 377 & 350 & 334 & 12,1 \\
Mensalista & 296 & 225 & 391 & 385 & 358 & 344 & 16,2 \\
Diarista & 301 & 205 & 400 & 346 & 316 & 297 & $-1,3$ \\
\hline
\end{tabular}

Fonte: Convênio D ieese/ Seade. PED - (Pesquisa de E mprego e D esemprego).

(1) Exclusive os assalariados e os empregados domésticos assalariados que não tiveram remuneração no mês, os trabalhadores familiares sem remuneração salarial e os trabalhadores que ganharam exclusivamente em espécie ou beneficio. Inflator utilizado: ICV do Dieese.

(2) Inclusive a categoria $O$ utras Posições na $O$ cupação.

(3) Inclusive aqueles que não sabem a que setor pertence a empresa em que trabalham.

A penas as categorias com menores rendimentos, ou seja, os empregados domésticos e os assalariados sem carteira assinada, foram os que tiveram evolução relativamente mais favorável de sua renda, com uma recuperação mais consolidada nos anos seguintes ao controle da inflação. As maiores perdas nos rendimentos foram verificadas para os trabalhadores autônomos, que trabalham para o público ou para empresas. Os assalariados com carteira assinada pelo setor privado e os empregados do setor público tiveram menor queda. 0 aumento dos rendimentos reais dos empregados domésticos e assalariados sem carteira (que além de mais desprotegidos são os que ganham menos) ocorreu num quadro de compressão geral dos rendimentos do trabalho e em especial de uma categoria também menos protegida, que é o trabalhador autônomo.

O Gráfico 5 permite visualizar o movimento dos salários médios reais para o conjunto dos assalariados, autônomos e empregados domésticos, 1989 a 2001.

Finalmente, a Tabela 11 evidencia que, a partir de 1995, o grupo 3, que agrega $30 \%$ dos trabalhadores com maiores rendimentos, perdeu ligeiramente sua participação no total de rendimentos do trabalho. Ao mesmo tempo, os 30\% com rendimentos mais baixos ( grupo 1) e aquele pertencente à faixa intermediária (grupo 2) aumentaram suas respectivas parcelas na massa desses rendimentos, 
indicativo de pequena melhora na distribuição da renda gerada pelo trabalho e de menor perda no valor médio dos rendimentos reais destes dois últimos grupos de trabalhadores.

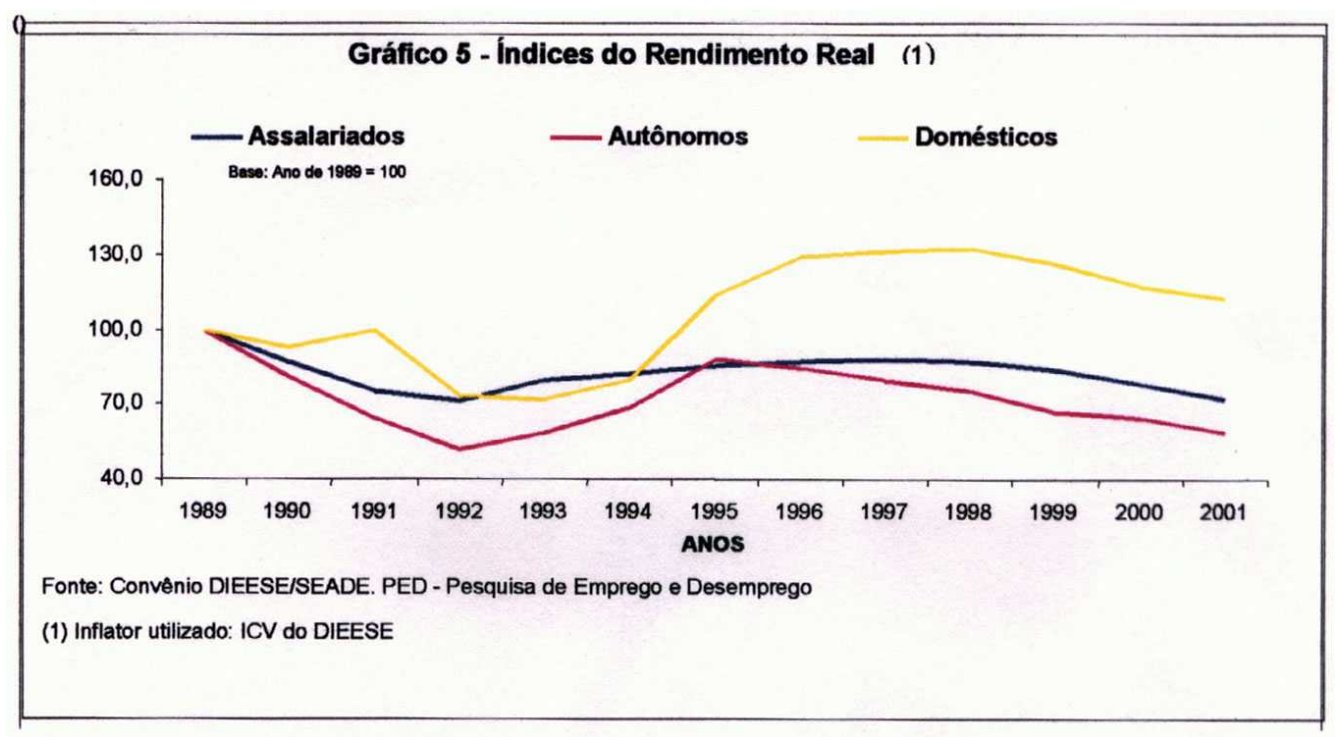

Tabela 11

Rendimento M édio e Distribuição da M assa de Rendimentos do

Trabalho Principal dos 0 cupados, por Grupos de Rendimento Região M etropolitana de São Paulo (1995-2002)

\begin{tabular}{lcccc}
\hline $\begin{array}{l}\text { Anos e Rendimento } \\
\text { Médio }\end{array}$ & Total & Grupo 1 & Gruoo 2 & Grupo 3 \\
\hline 1995 & 100,0 & 6,4 & 23,3 & 70,3 \\
Rendimento Médio & 1.128 & 240 & 657 & 2.643 \\
1996 & 100,0 & 6,8 & 23,4 & 69,9 \\
Rendimento Médio & 1.124 & 254 & 658 & 2.617 \\
1997 & 100,0 & 6,8 & 23,4 & 69,8 \\
Rendimento Médio & 1.126 & 255 & 659 & 2.620 \\
1998 & 100,0 & 7,1 & 23,7 & 69,2 \\
Rendimento Médio & 1.089 & 257 & 645 & 2.514 \\
1999 & 100,0 & 7,0 & 23,5 & 69,4 \\
Rendimento Médio & 1.028 & 241 & 605 & 2.381 \\
2000 & 100,0 & 7,0 & 23,5 & 69,5 \\
Rendimento Médio & 966 & 225 & 567 & 2.238 \\
2001 & 100,0 & 7,4 & $\mathbf{2 4 , 5}$ & $\mathbf{6 8 , 2}$ \\
Rendimento Médio & 880 & 216 & 539 & 2.001 \\
2002 & 100,0 & 7,5 & $\mathbf{2 4 , 8}$ & $\mathbf{6 7 , 7}$ \\
Rendimento Médio & 807 & 202 & 501 & 1.822 \\
\hline
\end{tabular}

Fonte: Convênio D ieese/ Seade. PED - (Pesquisa de Emprego e D esemprego).

N ota: I nflator utilizado: ICV do D ieese. Grupo 1 corresponde aos 30\% dos ocupados com menores rendimentos do trabalho principal, Grupo 2 corresponde aos $40 \%$ dos ocupados com rendimentos do trabalho principal imediatamente superiores aos do Grupo 1 e o Grupo 3 corresponde aos 30\% dos ocupados com maiores rendimentos do trabalho principal.

(1) Valores em reais de N ovembro de 2001. 
Contudo, no período recente, essa aparente melhora na distribuição dos rendimentos do trabalho pode estar revelando um paradoxo: em vez de melhora para todos os segmentos, desde 1997 observa-se queda dos rendimentos médios para os grupos de maior rendimento. Para o grupo 1, de menor rendimento, a queda é contínua desde 1998. Além disso, a queda é relativamente mais intensa para os grupos de renda mais alta. E m outras palavras, num quadro geral de queda dos rendimentos para toda a população ocupada, cai ainda mais a renda dos segmentos superiores, o que sugere uma "melhora da distribuição de renda" num momento em que todos perdem poder aquisitivo. A distribuição de renda na região metropolitana de São Paulo pode estar melhorando pela retração dos rendimentos médios da população ocupada, um fenômeno inverso ao "bolo" do milagre econômico que agora está encolhendo em vez de crescer.

\section{E volução e características do desemprego 1989-2001}

O desemprego captado pela PED e medido pelos indicadores aqui considerados compreende não só o desemprego aberto, ou seja, pessoa sem algum trabalho e com procura de trabalho nos últimos trinta dias, mas também o desemprego oculto pelo exercício de trabalho precário e o desemprego oculto pelo desalento da procura .E sta forma de aferição busca expressar mais precisamente a realidade do desemprego como carência de postos de trabal ho para incorporar como ocupada toda a PEA deste mercado de trabalho.

D esta forma, além da situação clara de não-trabal ho e procura de trabalho, compreendida no desemprego aberto, considera duas situações ocultas de desemprego:

- aquela que combina o exercício de trabalhos casuais de auto-ocupação, como forma de sobrevivência, com a procura de emprego (definida pela pesquisa como desemprego oculto pelo trabalho precário) e;

- aquela em que o desempregado, embora tenha necessidade e disponibilidade de trabalhar, encontra-se desestimulado a continuar procurando trabaIho devido às dificuldades em encontrar um posto (desemprego oculto pelo desalento da procura).

Estas duas últimas situações - desemprego oculto pelo trabal ho precário e desemprego oculto pelo desalento - procuram explicitar algumas formas de exclusão ocupacional que estão na fronteira entre desemprego e ocupação e entre desemprego e inatividade, relevantes em mercados de trabalho heterogêneos e sociedades marcadas por grandes desigualdades, com parcelas de população vivendo nos limites da pobreza e com escassa ou nenhuma proteção social. D esta forma, os indicadores referentes ao desemprego devem ser capazes de proporcionar informações não só sobre a incapacidade da economia de gerar postos de trabalho, mas também sobre a possibilidade de medir a exclusão social pela privação de acesso a um dos principais meios de sobrevivência e de integração social. 
O s indicadores apresentados a seguir evidenciam as conseqüências das modificações e a falta de dinamismo do mercado de trabalho sobre a parcela não absorvida de sua População E conomicamente Ativa. 0 Gráfico 6 apresenta a evolução da taxa de desemprego total e sua decomposição nos três tipos de desemprego aferidos pela PED.

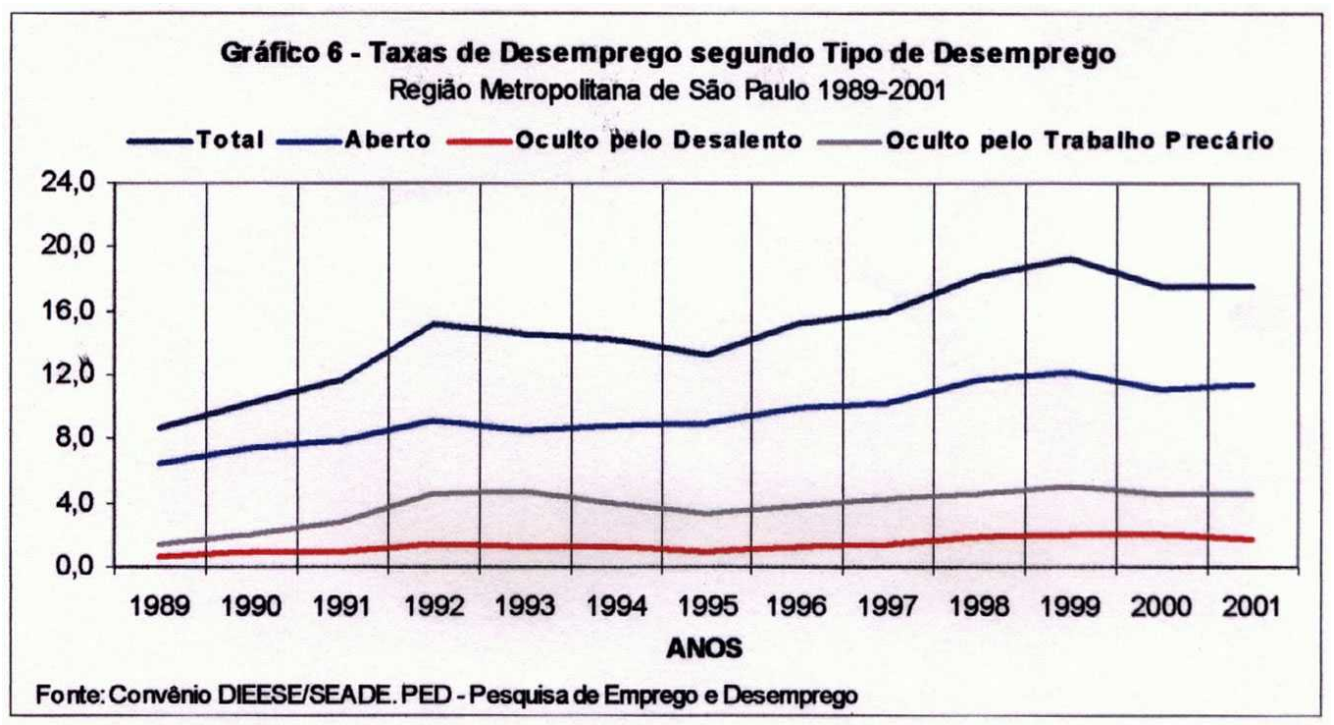

Como pode ser observado, a taxa de desemprego total e as frações que corres-pondem a seus três componentes apresentam clara mudança de patamar. A taxa de desemprego praticamente dobra entre 1989 e 1992, início do governo Collor e da abertura econômica. D epois de apresentar queda entre 1993 e 1995 volta a subir, sobretudo a partir de 1997, atingindo seu maior valor em 1999.

O desemprego aberto é o principal componente do desemprego total e apresenta, junto com o desemprego oculto pelo trabalho precário, as maiores variações. 0 desemprego oculto pelo desalento representa parcela bem menor de desempregados e é bastante estável sua evolução. Cabe alertar que tal comportamento é em parte resultado da forma operacional de sua captação, que exclui desta situação, levando para a inatividade, parte dos desalentados da procura, uma vez que só considera aqueles indivíduos que descontinuaram a busca por trabalho nos últimos doze meses.

Como resultado desta tendência, em 2001, o desemprego continuou afetando parte substantiva da PEA residente na R egião M etropolitana de São Paulo $(17,6 \%)$. A taxa foi igual à verificada em 2000 e 1,7 pp menor que a de 1999, quando atingiu 19,3\%, a maior de toda a série histórica da PED, iniciada em 1985. Em 2001, mais 31 mil trabalhadores entraram na situação de desemprego, elevando para 1,622 milhões o total de desempregados. D estes, 1.041 milhões encontravam-se na situação de desemprego aberto e 581 mil, de desemprego oculto pelo trabalho precário ou desalento, que representou cerca de $36 \%$ do total de desemprego aferido pela PED. 
Tabela 12

Taxas de D esemprego e Estimativas de D esempregados, segundo Tipo de D esemprego.

Região M etropolitana de São Paulo, 1989-2001.

\begin{tabular}{|c|c|c|c|c|c|c|}
\hline Taxas de Desemprego e Estimativas & 1989 & 1992 & 1997 & 1999 & 2000 & 2001 \\
\hline \multicolumn{7}{|l|}{ Desemprego Total } \\
\hline Taxa (em \%) & 8,7 & 15,2 & 16,0 & 19,3 & 17,6 & 17,6 \\
\hline Desempregados (em 1.000 pessoas) & 614 & 1.175 & 1.375 & 1.715 & 1.591 & 1.622 \\
\hline \multicolumn{7}{|l|}{ Desemprego Aberto } \\
\hline Taxa (em \%) & 6,5 & 9,2 & 10,3 & 12,1 & 11,0 & 11,3 \\
\hline Desempregados (em 1.000 pessoas) & 458 & 711 & 885 & 1.075 & 995 & 1.041 \\
\hline \multicolumn{7}{|l|}{ Desemprego Oculto pelo Desalento } \\
\hline Taxa (em \%) & 0,7 & 1,4 & 1,5 & 2,1 & 2,0 & 1,7 \\
\hline Desempregados (em 1.000 pesscas) & 49 & 108 & 129 & 187 & 181 & 157 \\
\hline \multicolumn{7}{|c|}{ Desemprego Oculto pelo Trabalho Prectrio } \\
\hline $\operatorname{Taxa}(\mathrm{em} \%)$ & 1,5 & 4,6 & 4,2 & 5,1 & 4,6 & 4,6 \\
\hline Desempregados (em 1.000 pesscas) & 106 & 356 & 361 & 453 & 416 & 424 \\
\hline
\end{tabular}

Fonte: Convênio Dieese/ Seade. PED - (Pesquisa de Emprego e D esemprego).

As dificuldades da economia em gerar postos de trabalho suficientes para atender à demanda da população são expressas também pela duração da situação do desemprego. Q uanto menores as oportunidades de trabalho, mais prolongada é a duração do desemprego. U m indicador desta duração é o tempo de procura de trabalho pelos desempregados.

No período analisado, verificou-se substancial aumento no tempo médio de procura, que passou de quinze semanas, em 1989, para 44 semanas, em 1999, e alcançou 48 semanas, em 2001. O desemprego de longa duração ganhou peso no decorrer dos anos de 1990. N os últimos três anos do período analisado, passou a afetar mais de $20 \%$ dos desempregados. Esta proporção, em 1989, era de apenas $2,9 \%$

Tabela 13

D uração M édia da Procura de Trabalho e Proporção de D esempregos com mais de 12 M eses de Procura Região M etropolitana de São Paulo (1989-2001)

\begin{tabular}{lccc}
\hline Duração de Procura de Trabalho & 1999 & 1999 & 2001 \\
\hline Duração Média da Procura de Trabalho (em semanas) & 15 & 44 & 48 \\
Percentual de Desempregados com mais de 12 meses de Procura & 2,9 & 21,8 & 22,3 \\
\hline
\end{tabular}

Fonte: Convênio Dieese/ Seade. PED - (Pesquisa de Emprego e D esemprego). 
A especificação das taxas de desemprego por atributos pessoais indica generalização e intensificação do desemprego, que passou a atingir, de forma acentuada, segmentos de trabalhadores até então menos vulneráveis, como chefes de domicílio, homens e trabalhadores de ambos os sexos, na faixa etária mais produtiva (Tabela 14). A taxa de desemprego dos homens praticamente dobrou entre 1989 e 2001. M ais intensa, entretanto, foi a elevação das taxas para os chefes de domicílio e trabalhadores de 25 a 39 anos que cresceram 153,7\% e 121,0\% respectivamente, no mesmo período.

Tabela 14

Taxa de D esemprego, segundo Atributos Pessoais

Região M etropolitana de São Paulo (1989-2001)

\begin{tabular}{|c|c|c|c|c|c|c|}
\hline Atributos & 1989 & 1992 & 1997 & 1999 & 2000 & 2001 \\
\hline TOTAL & 8,7 & 15,2 & 16,0 & 19,3 & 17,6 & 17,6 \\
\hline \multicolumn{7}{|c|}{ Posição no Domicílio } \\
\hline Chefe & 4,1 & 8,9 & 9,6 & 11,8 & 10,2 & 10,4 \\
\hline Cônjuge & 8,6 & 14,7 & 14,9 & 19,0 & 19,0 & 18,3 \\
\hline Filho & 14,9 & 24,1 & 25,6 & 29,5 & 27,1 & 26,5 \\
\hline Outros & 10,0 & 17,1 & 18,1 & 22,9 & 19,4 & 20,9 \\
\hline \multicolumn{7}{|l|}{ Sexo } \\
\hline Homens & 7,5 & 13,9 & 14,2 & 17,3 & 15,0 & 14,9 \\
\hline Mulheres & 10,6 & 17,1 & 18,3 & 21,7 & 20,9 & 20,8 \\
\hline \multicolumn{7}{|l|}{ Faixa Etária } \\
\hline 10 a 14 Anos & 32,1 & 43,9 & 42,6 & 49,7 & 47,5 & 48,3 \\
\hline 15 a 17 Anos & 21,9 & 36,7 & 40,8 & 48,7 & 46,5 & 47,0 \\
\hline 18 a 24 Anos & 11,9 & 20,8 & 22,4 & 27,5 & 25,3 & 25,2 \\
\hline 25 a 39 Anos & 6,2 & 12,0 & 12,7 & 15,4 & 14,0 & 13,7 \\
\hline 40 Anos e Mais & 3,5 & 8,1 & 9,2 & 12,2 & 11,0 & 11,3 \\
\hline
\end{tabular}

Fonte: Convênio D ieese/ Seade. PED - (Pesquisa de Emprego e D esemprego).

E m 2001, estavam desempregados cerca de 15\% dos homens economicamente ativos, 13,7\% dos trabalhadores, de ambos os sexos, de 25 a 39 anos, e 10,4\% dos chefes de domicílio, cujas taxas de desemprego, para o início do período, eram respectivamente de $7,5 \%, 6,2 \%$ e $4,1 \%$. E ste aumento pode ser considerado a expressão mais direta da perda de dinamismo do mercado de trabalho e até mesmo da destruição de um conjunto de postos no período. Cabe lembrar que estes segmentos de trabalhadores são os de maior constância e presença no mercado de trabalho e os que geralmente estão na situação de ocupados.

Do ponto de vista social merecem destaque o crescimento do desemprego entre os chefes de domicílio, que, na maior parte dos casos, são os principais provedores da família, e a elevação das taxas de desemprego dos cônjuges, revelando suas dificuldades de cooperar para a manutenção dos rendimentos familia- 
res, na hipótese do desemprego do chefe de domicílio. A maior participação do cônjuge no mercado de trabalho, como antes comentado, acaba, em parte, frustrada, em um mercado de trabal ho pouco dinâmico, que el eva sua taxa específica de desemprego para valores acima de 18\%, de 1999 a 2001.

As modificações da dinâmica ocupacional refletem-se também nos indicadores relativos à experiência anterior de trabalho dos desempregados. Tais indicadores mostram que, entre 1989 e 2001, o desemprego não só aumentou para aqueles com experiência anterior de trabalho, e que portanto buscam nova inserção ocupacional, como também mudaram as características do último trabalho exercido.

Tabela 15

D istribuição dos D esempregados com e sem Experiência Anterior de Trabalho, segundo Posição na O cupação e Setor de Atividade no Ú Itimo Trabalho

Região M etropolitana de São Paulo (1989-2001).

\begin{tabular}{|c|c|c|c|}
\hline & & & (om \% \\
\hline $\begin{array}{c}\text { Experiência de Trabalho e Posição na Ocupação e } \\
\text { Setor de Atividade no Último Trabalho }\end{array}$ & 1989 & 1999 & 2001 \\
\hline Total de Desempregados & 100,0 & 100,0 & 100,0 \\
\hline Com Experiência & 85,0 & 86,7 & 86,1 \\
\hline Sem Experiência & 15,0 & 13,3 & 13,9 \\
\hline $\begin{array}{l}\text { Desempregados com Experiência } \\
\text { Posição na Ocupação }\end{array}$ & 100,0 & 100,0 & 100,0 \\
\hline Assalariado & 83,7 & 76,3 & 72,4 \\
\hline Autônomo & 8,5 & 12,0 & 14,3 \\
\hline Empregado Doméstico & 6.9 & 10,2 & 11,9 \\
\hline Outras & 0,9 & 1,5 & 1,5 \\
\hline \multicolumn{4}{|l|}{ Setor de Atividade } \\
\hline Indústria de Transformaçăo & 38,4 & 24,4 & 22,7 \\
\hline Comércio & 17,1 & 16,9 & 16,5 \\
\hline Serviços & 31,3 & 43,4 & 44,3 \\
\hline Serviços Domésticos & 6,9 & 10,2 & 11,9 \\
\hline Outros & 6,3 & 5,1 & 4,6 \\
\hline
\end{tabular}

Fonte: Convênio Dieese/ Seade. PED - (Pesquisa de Emprego e D esemprego).

O trabalho assalariado, como última forma de inserção ocupacional, perdeu importância, assim como o setor industrial. Por outro lado, aumentou a participação do trabal ho autônomo, dos empregados domésticos e daqueles cuja última experiência como ocupado foi nos setores de serviços ou do comércio. Esta última situação reproduz a tendência verificada na estrutura de postos de trabal ho dos ocupados, gerada pelo menor crescimento da indústria e à expansão dos segmentos de trabalhos não-assalariados e dos serviços e do comércio. Em decorrência destas modificações ocupacionais, ao longo dos anos de 1990, as características da última reinserção dos atuais desempregados como ocupados tendem a ser cada vez mais espelho da perda de dinamismo ocupacional do setor industrial e do assalariamento na região. 


\section{C onsiderações finais}

As evidências estatísticas apresentadas indicam que, na década de 1990 e no início da atual, o mercado de trabalho na R egião M etropolitana de São Paulo vem sofrendo um processo acentuado de deterioração, tanto na capacidade de atender às demandas da população por trabalho, como nas características dos postos de trabal ho gerados e nos valores dos rendimentos auferidos.

A indústria foi a principal responsável pela perda de dinamismo do mercado de trabalho na região. Coube aos setores de serviços e comércio compensar, em parte, a queda absoluta do nível de ocupação industrial. Acompanhando esta situação, cresceu o número de trabalhadores ocupados como autônomos e empregados domésticos, bem como o de assalariados sem carteira de trabalho assinada. 0 trabalho assalariado em geral diminuiu, em particular o com carteira assinada no setor privado e, em menor medida, o emprego no setor público.

Além do assalariamento sem carteira de trabalho (a principal e mais tradicional forma de flexibilização da contratação pelos empregadores do setor privado), cresceu a ocupação terceirizada, por meio de empresas prestadoras de serviços ou da contratação direta do trabalhador como autônomo. Este processo, aliás, também passou a ser utilizado pelo setor público, embora em menor proporção.

O s rendimentos médios reais para o conjunto de ocupados e para as diferentes catego rias ocupacionais (com exceção dos empregados domésticos e assalariad os sem carteira de trabalho) foram reduzidos, apesar de apresentarem recuperação nos anos iniciais do Plano Real. Ao final do período analisado, estavam ainda em níveis bem inferiores aos verificados no final dos anos de 1980. Como um espelho destas modificações na dinâmica de crescimento ocupacional, verificou-se, neste período, as maiores taxas de desemprego desde 1985, ano inicial da série histórica da PED , e o aumento do desemprego de longa duração.

Ao mesmo tempo, o desemprego se generalizou, atingindo fortemente segmentos da força de trabalho, geralmente menos vulneráveis, como trabalhadores na faixa etária de 25 a 39 anos, chefes de domicílio/ família e trabalhadores do sexo masculino. Aumentou também o número de desempregados em busca de uma nova inserção e diminuiu a proporção daqueles anteriormente assalariados e aqueles cujo último trabalho foi no setor industrial.

Cabe assinalar que indicadores recentemente divulgados pela PED, para 2002, mostram a persistência do quadro anteriormente desenhado, no qual destacam-se a elevação da taxa de desemprego para 19\% (segunda maior taxa da série histórica da pesquisa); queda de $8,3 \%$ no valor dos rendimentos médios do total de ocupados e crescimento de apenas $0,4 \%$ do nível de ocupação total, com ampliação do trabalho autônomo e do emprego doméstico. A ocupação industrial apresentou leve crescimento $(0,9 \%)$ e os níveis de ocupação do setor de serviços e de comércio foram reduzidos. Pela primeira vez, desde o início da PED em 1985, não se observou evolução positiva do nível de ocupação no setor 
de serviços, setor que mais emprega pessoas na região. Tal fato certamente esteve associado à enorme queda dos rendimentos do trabalho no ano passado $(-8,3 \%)$ e no período 1997-2002 (-28,3\%) uma vez que a dinâmica ocupacional dos serviços está muito ligada ao nível de renda da população no mercado doméstico.

I nfelizmente, três anos após o início da década e do milênio, não se observam modificações nas tendências de desestruturação do mercado de trabalho na maior região metropolitana do país. Sem que a economia brasileira e a economia paulista retomem o ritmo de crescimento observado até os anos de 1980, dificilmente teremos alterações significativas nas tendências apontadas nesse texto.

Nota

1 As taxas de participação representam a proporção de indivíduos acima de dez anos que se encontram no mercado de trabalho naquele segmento específico da força de trabalho (sexo, faixa etária, posição no domicílio etc.).

Bibliografia

BALTAR, P. E. A.; DEDECCA, C. S. e HENRIQUE, W. (1996). "M ercado de trabaIho e exclusão social no Brasil". E m O LIVEIRA, C. A. B.; M ATTOSO , J. E. L. Crise etrabalho no Brasil: modernidade ou vol ta ao passado? São Paulo, Scritta.

BESSO N, J. L. (1995). "As estatísticas: verdadeiras ou falsas?" Em BESSO N , J. L. (org.). A ilusão das estatísticas. Trad. E mir Sader. São Paulo, U nesp.

BU SSAB,W. O . e DINI, N. P. (1985). "Regiões homogêneas na Grande São Paulo". R evista da Fundação Seade. São Paulo, vol. 1, n. 3.

CACCIAMALLI, M. C. (1983). Setor Informal urbano e formas de participação na produção. São Paulo, IPE-U SP.

CÉZARD, M . (1996). "Le chômage et son halo". Economieet Statistique Paris, n. 193-4.

COMISSÃO ECON ÔM ICA PARA AM ÉRICA LATIN A E CARIBE - CEPAL. (1979). La medición del empleo y delosingressosen areasurbanasatraves de encuestas de hogares. Santiago do Chile, Cepal, ago. Informe Final do Grupo de Trabalho.

DEDECCA, C. S. (1997). D esemprego no Brasil: um fenômeno heter ogêneo. Campinas, U nicamp- IE-C esit, (Boletim do C esit, 1).

DIEESE. (2001). A situação do trabalho no Brasil. São Paulo.

DIEESE e SEADE. (1995). Pesquisa de emprego e desemprego: relatório metodológico. mimeo.

DIEESE; I N SPIR e AFL-CIO . (1999). M apa da população negra no mercado detrabaIho. São Paulo.

FREYSSINET, J. (1994). Lechômage Paris, La D écouverte.

H OFFM AN N, M. P. e BRAN DÃO, S. M . C. (1996). M edição do emprego: recomendações da OIT e práticas nacionais Campinas, U nicamp-IE-Cesit, (C adernos do Cesit, 22). 
HOFFM AN N, M. P. e CUTRIM, M. A. B. Unemployment in Brazil: H ow can it be M easured? D isponível em: http:// www1.msh.paris.fr/ reseau emploi/chatiersencours/ unemplbrasil.rtf

H U SSM AN N S, R.; M EH RAN, F. e VERM A, V. (1990). Sur veys of EconomicallyA ctive Population, Employment, U nemployment and U nderemployment: A I I O M anual on Concepts and M ethods G eneva, ILO .

INSTITUTO BRASILEIRO DE GEOGRAFIA E ESTATÍSTICA - IBGE. (1983). M etodologia da Pesquisa M ensal de Emprego: 1980. Rio de Janeiro, IBGE, (Série Relatórios M etodológicos, 2).

INTERN ATIO N AL LABO U R ORGAN IZATIO N - ILO . (1983). R esolution C oncerning Statistics of the Economically A ctive Population, Employment, U nemployment and U nderemployment: R esolution I I International C onference of L abour Statisticians, 13. Geneva, I LO.

"Projeto de resolução I: M edição do subemprego". (1998). Conferência Internacional de Estatísitca do Trabalho, 16. Genebra, ILO, out.

M EN D O N ÇA, Sérgio E duardo Arbulu e H OFFM AN N, M arise Borém Pimenta. (1999). "A pesquisa de emprego de desemprego - PED: inovações metodológicas". Em DIEESE (org.). Emprego edesenvolvi mento tecnológico: processosdeintegração regi onal. São Paulo, DIEESE/ CESIT, 1999 (Seminários Internacional e R egionais “Emprego e D esenvolvimento Tecnológico").

M ONTAGNER, P. e BRANDÃO, S. M. C. (1996). "N ovas Características do D esemprego". Encontro $\mathrm{N}$ acional de Estudos Populacionais, 10. Belo H orizonte, ABEP, vol. 1 , pp. 437-464.

PO K, C. e TRABU CH I, C. C. (1995). "Encuesta Permanente de H ogares: D esarrolllo Actual y Perspectivas". Seminário I nternacional sobre M ediacion del Empleo, Buenos Aires, INDEC, dez., mimeo.

PROGRAMA REGIONAL DEL EM PLEO PARA AM ERICA LATINA E EL CARIBE - PREALC. (1981). Dinámica del subempleo en A merica Latina. Santiago do Chile, CEPAL, ago., (Estudios e Informe). PREALC, OIT.

(1991). Empleo y Equidad: El Desafio de los 90. Santiago do Chile,

SAN CHES, S. et al. (2002). "O sistema PED: pesquisa de emprego e desemprego em seis regiões metropolitanas". Em WILTGEN , S. R. e GARCIA, S. L. Transformações do mercado de trabalho metropolitano: 10 anos da PED-R M PA, Porto Alegre, FEE

TO KM AN , V. E. (1990). "The I nformal Sector in Latin America: Fiftheen Years L ater". Em TURN H AM , D.; B.SALOM E eA. SCH WARS (eds.). Thel nformal sector R eviseted. Geneva, OCDE.

TRO YAN O , A. A. et al. (1985). "A necessidade de uma nova conceituação de emprego e desemprego". R evista da Fundação Seade. São Paulo, vol .1, n. 1.

M arise Borém Pimenta H offmann é socióloga, analista técnica do DIEESE e consultora da Fundação Seade - SP.

Sérgi o Eduardo A rbulu M endonça é economista e diretor técnico do DIEESE. 